\title{
BADANIA WYTRZYMAŁOŚCI NA ŚCINANIE GEOKOMPOZYTÓW WYKONANYCH Z PAKIETÓW SPRASOWANYCH ZUŻYTYCH OPON I MATERIAŁU ZASYPOWEGO
}

\author{
Aleksander Duda ${ }^{\bowtie}$, Dariusz Sobala, Tomasz Siwowski \\ Wydział Budownictwa, Inżynierii Środowiska i Architektury, Politechnika Rzeszowska, Rzeszów
}

\begin{abstract}
STRESZCZENIE
Pakiety gumowe ze sprasowanych zużytych opon samochodowych (SZOS) to nowy materiał budowlany $\mathrm{z}$ recyklingu do stosowania w budownictwie komunikacyjnym. Materiał ten charakteryzuje się małym ciężarem objętościowym, bardzo dobrymi właściwościami drenażowymi oraz dużą zdolnością do tłumienia drgań. Celem badań była ocena pracy geokompozytów złożonych z pakietów SZOS i materiałów zasypowych (keramzyt, kruszywo gumowe $4 \div 20 \mathrm{~mm}$, piasek), stosowanych w budowlach ziemnych w infrastrukturze komunikacyjnej. Przeprowadzono badania tarcia/poślizgu pomiędzy materiałem zasypowym a gumą pakietów oraz badania wytrzymałości na ścinanie geokompozytów z pakietów SZOS i materiału zasypowego. Wyniki badań wykazały duże opory ścinania (kąty tarcia wewnętrznego) pomiędzy pakietami a materiałami zasypowymi i potwierdziły możliwość technicznie efektywnego ich wykorzystania w budowlach ziemnych infrastruktury komunikacyjnej.
\end{abstract}

Słowa kluczowe: recykling opon, pakiety z opon, geokompozyt, materiał zasypowy, budowle ziemne

\section{WSTĘP}

Przedmiotem badań omówionych w artykule jest nowy materiał budowlany pochodzący z recyklingu sprasowanych zużytych opon samochodowych (SZOS) w postaci pakietów. Zużyte opony są ściskane w specjalnej prasie, następnie spinane taśmami z tworzyw lub ocynkowanymi drutami ze stali sprężynowej o dużej wytrzymałości. Pakiet SZOS ma kształt zbliżony do prostopadłościanu (rys. 1). Wysokość pakietu jest z reguły równa średnicy sprasowanych opon, a szerokość i długość zależy od liczby użytych opon (zwykle 100 $\div 140$ sztuk), parametrów technicznych wykorzystanej prasy (tj. wymiaru komory i siły prasowania) oraz długości elementów spinających. Prasowanie zużytych opon do formy pakietów umożliwia 3,4-krotne ograniczenie przestrzeni ich składowania $\mathrm{w}$ stosunku do składowania w stanie luźnym. W podobnym stopniu wzrasta efektywność transportowa zużytych opon w formie pakietów (Duda i Trojnar, 2016; Duda, Sobala, Siwowski i Kaleta, 2016).

Główne właściwości fizyczne i mechaniczne pakietów SZOS, ustalone na podstawie badań własnych i studiów piśmiennictwa, zestawiono i porównano w tabeli $1 \mathrm{z}$ analogicznymi parametrami kruszywa mineralnego.

Planowanym głównym obszarem masowego wykorzystania materiału z recyklingu w formie pakietów SZOS są wszelkiego rodzaju komunikacyjne budowle ziemne, np. korpusy nasypów drogowych, strefy dojazdowe do przyczółków obiektów mostowych oraz konstrukcje oporowe. Przeprowadzone badania miały

凶aduda@prz.edu.pl 


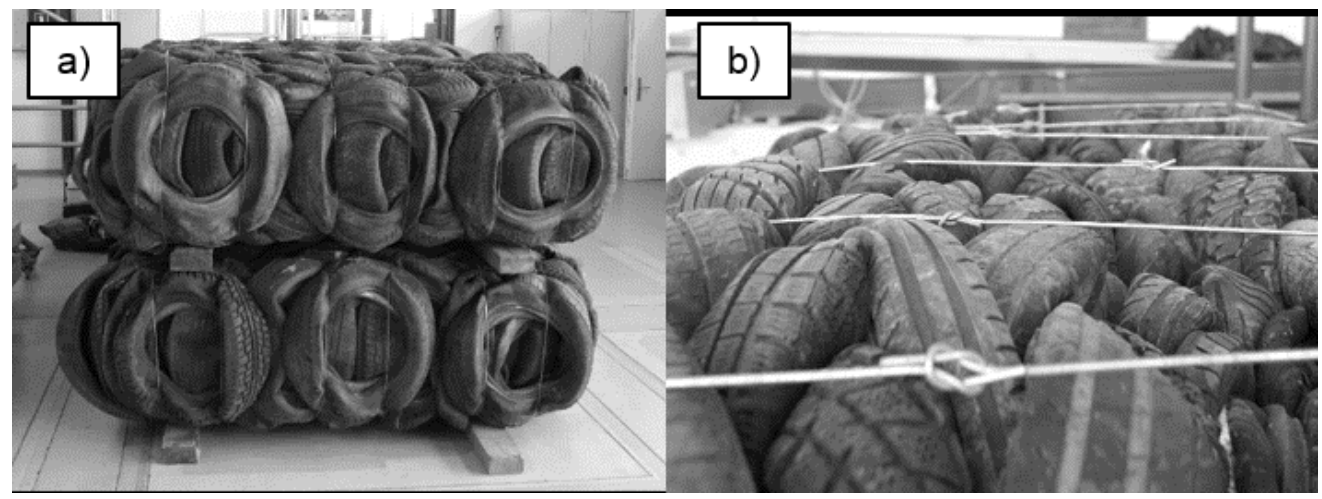

Rys. 1. Pakiety SZOS (a), połączenie drutów spinających pakiety (b)

Fig. 1. Tire bales (a), connection wires spanning the tire bales (b)

Tabela 1. Porównanie właściwości pakietów SZOS z kruszywami naturalnymi

Table 1. Comparison of the properties of tire bales with natural aggregates

\begin{tabular}{|c|c|c|c|}
\hline $\begin{array}{l}\text { Cecha } \\
\text { Feature }\end{array}$ & $\begin{array}{l}\text { Pakiety SZOS } \\
\text { Tire bales }\end{array}$ & $\begin{array}{l}\text { Kruszywo mineralne } \\
\text { (piaski, żwiry) } \\
\text { Minerals (sand, gravel) }\end{array}$ & $\begin{array}{l}\text { Źródło } \\
\text { Source }\end{array}$ \\
\hline $\begin{array}{l}\text { Ciężar objętościowy }\left[\mathrm{kN} \cdot \mathrm{m}^{-3}\right] \\
\text { Unit weight }\end{array}$ & $5 \div 6$ & $18 \div 20$ & PAS-108 2007 \\
\hline $\begin{array}{l}\text { Kąt tarcia }\left[{ }^{\circ}\right]^{a} \\
\text { Friction angle }\end{array}$ & $35 \div 36$ & {$[-]$} & $\begin{array}{l}\text { Zornberg, Christopher } \\
\text { i Oosterbaan (2005) }\end{array}$ \\
\hline $\begin{array}{l}\text { Kąt tarcia wewnętrznego }\left[^{\circ}\right] \\
\text { Friction angle }\end{array}$ & {$[-]$} & $35 \div 40$ & {$[-]$} \\
\hline $\begin{array}{l}\text { Moduł odkształcenia [MPa] } \\
\text { Elastic modulus }\end{array}$ & $0,8 \div 1,3$ & $40 \div 100$ & PAS-108 2007 \\
\hline $\begin{array}{l}\text { Współczynnik filtracji }\left[\mathrm{cm} \cdot \mathrm{s}^{-1}\right] \\
\text { Permeability coefficient }\end{array}$ & $2 \div 4$ & $0,1 \div 1$ & PAS-108 2007 \\
\hline $\begin{array}{l}\text { Przewodność cieplna }\left[\mathrm{W} \cdot(\mathrm{m} \cdot \mathrm{K})^{-1}\right] \\
\text { Thermal conductivity }\end{array}$ & 0,07 & $0,4 \div 0,7$ & Zornberg i in. 2005 \\
\hline $\begin{array}{l}\text { Wibroizolacyjność } \\
\text { Vibro insulation }\end{array}$ & $\begin{array}{l}\text { bardzo wysoka } \\
\text { very high }\end{array}$ & $\begin{array}{c}\text { niska } \\
\text { low }\end{array}$ & Zornberg i in. 2005 \\
\hline
\end{tabular}

a Wartość odnosi się do poślizgu między pakietami bez warstwy zasypki.

${ }^{a}$ Value refers to the friction between tire bales without backfill.

na celu ustalenie wartości jednego z podstawowych parametrów wykorzystywanych w projektowaniu tego typu budowli, jakim jest wartość kąta tarcia pakietów sprasowanych opon po podłożu gruntowym/materiale zasypowym i ewentualne potwierdzenie wartości podawanych w piśmiennictwie (PAS-108 2007; Zornberg, Christopher i Oosterbaan, 2005). Badania wykonano z użyciem pakietów SZOS, zmieniając rodzaj materiału zasypowego (warstwy kontaktowej) między pakietami. Dobór materiału zasypowego był podyktowany potrzebą opracowania geokompozytu najtańszego, najlżejszego lub/i w największym stopniu wykorzystującego materiał $\mathrm{z}$ recyklingu. 
Duda, A., Sobala, D. i Siwowski,T. (2017). Badania wytrzymałości na ścinanie geokompozytów wykonanych z pakietów sprasowanych zużytych opon i materiału zasypowego. Acta Sci. Pol. Architectura, 16 (3), 3-12. doi: 10.22630/ASPA.2017.16.3.01.

\section{MATERIAL I METODY}

\section{Materiały wykorzystane w badaniach}

Badanie przeprowadzono, wykorzystując trzy pakiety SZOS (P1, P2 i P3) o wymiarach i ciężarze podanych w tabeli 2.

Tabela 2. Charakterystyka pakietów - próbek badawczych

Table 2. Characteristics of tire bales - test specimens

\begin{tabular}{|c|c|c|c|c|}
\hline $\begin{array}{l}\text { Oznaczenie próbek } \\
\text { Specimen designation }\end{array}$ & $\begin{array}{l}\text { Długość } \\
\text { Lenght } \\
{[\mathrm{m}]}\end{array}$ & $\begin{array}{c}\text { Szerokość } \\
\text { Widht } \\
{[\mathrm{m}]}\end{array}$ & $\begin{array}{c}\text { Wysokość } \\
\text { Height } \\
\text { [m] }\end{array}$ & $\begin{array}{c}\text { Ciężar } \\
\text { Weight } \\
{[\mathrm{kN}]}\end{array}$ \\
\hline P1 & 2,05 & 1,31 & 0,74 & $10 \pm 0,2$ \\
\hline P2 & 2,07 & 1,31 & 0,75 & $10 \pm 0,2$ \\
\hline P3 & 2,07 & 1,32 & 0,75 & $10 \pm 0,2$ \\
\hline
\end{tabular}

Materiał zasypowy między pakietami wykonano kolejno z trzech rodzajów kruszyw, tj. piasku średniego, kruszywa gumowego stanowiącego mieszankę chipsów i granulatu gumowego (ang. Tire Derived Aggregate - TDA) oraz sztucznego keramzytu geotechnicznego. Charakterystykę wykorzystywanych materiałów zasypowych podano w tabeli 3 .

Tabela 3. Charakterystyka materiałów zasypowych

Table 3. Characteristics of backfill materials

\begin{tabular}{|c|c|c|c|c|c|c|}
\hline $\begin{array}{l}\text { Materiał zasypowy } \\
\text { Backfill material }\end{array}$ & $\begin{array}{c}\text { Uziarnienie } \\
\text { Granulation } \\
\text { [mm] }\end{array}$ & $\begin{array}{c}\text { Ciężar } \\
\text { nasypowy } \\
\text { Unit weight } \\
{\left[\mathrm{kN} \cdot \mathrm{m}^{-3}\right]}\end{array}$ & $\begin{array}{c}\text { Kąt tarcia we- } \\
\text { wnętrznego } \\
\text { Friction angle } \\
\left.{ }^{\circ}\right]\end{array}$ & $\begin{array}{c}\text { Wilgotność } \\
\text { Moisture } \\
{[\%]}\end{array}$ & $\begin{array}{c}\text { Stan gruntu } \\
\text { Soil state } \\
{[-]}\end{array}$ & $\begin{array}{c}\text { Źródło } \\
\text { Source } \\
{[-]}\end{array}$ \\
\hline $\begin{array}{l}\text { Piasek średni } \\
\text { Medium sand }\end{array}$ & $0,25 \div 1,00$ & $16,5 \pm 0,5$ & 35,2 & 12,$6 ; 12,8$ & $\begin{array}{l}\text { luźny - średnio } \\
\text { zagęszczony } \\
\text { loose - medium } \\
\text { concentrated }\end{array}$ & Raport ReUse \\
\hline $\begin{array}{l}\text { Kruszywo gumowe } \\
\text { Tire Derived Aggregate (TDA) }\end{array}$ & $4 \div 20$ & 4,2 & $35 \div 37$ & 9,$8 ; 11,0$ & $\begin{array}{l}\text { luźny } \\
\text { loose }\end{array}$ & $\begin{array}{l}\text { Geosyntec } \\
\quad(2008)\end{array}$ \\
\hline $\begin{array}{l}\text { Keramzyt } \\
\text { Light Expanded Clay } \\
\text { Aggregate (LECA) }\end{array}$ & $8 \div 20$ & 3,2 & 35,3 & 18,$7 ; 22,2$ & $\begin{array}{l}\text { luźny } \\
\text { loose }\end{array}$ & Raport ReUse \\
\hline
\end{tabular}

\section{Stanowisko badawcze}

Badanie wytrzymałości na ścinanie geokompozytu złożonego z pakietu SZOS i materiału zasypowego przeprowadzono w wielkowymiarowym stanowisku badawczym, specjalnie zaprojektowanym i zbudowanym w hali Wydziałowego Laboratorium Badań Konstrukcji Politechniki Rzeszowskiej (rys. 2). Stanowisko badawcze składało się z układu obciążenia/wymuszenia, badanej próbki geokompozytu, układu pomiarowego i balastu. Układ obciążenia składał się ze stalowych elementów oporowych zakotwionych w podłodze siłowej, siłownika poziomego generującego siłę do $40 \mathrm{kN}$ i balastu w postaci płyt drogowych o ustalonym ciężarze lub/i pakietu SZOS. 
Duda, A., Sobala, D. i Siwowski, T. (2017). Badania wytrzymałości na ścinanie geokompozytów wykonanych z pakietów sprasowanych zużytych opon i materiału zasypowego. Acta Sci. Pol. Architectura, 16 (3), 3-12. doi: 10.22630/ASPA.2017.16.3.01.

Badaniom poddano próbkę geokompozytu (pakiety SZOS, materiał zasypowy) uformowaną w samonośnej, wzmocnionej zastrzałami skrzyni drewnianej o wymiarach $2,4 \times 1,8 \times 1,0 \mathrm{~m}$. Przemieszczenia mierzone były czujnikami indukcyjnymi, a siłę mierzono czujnikiem siły. Na rysunku 2 pokazano schemat i widok stanowiska badawczego.
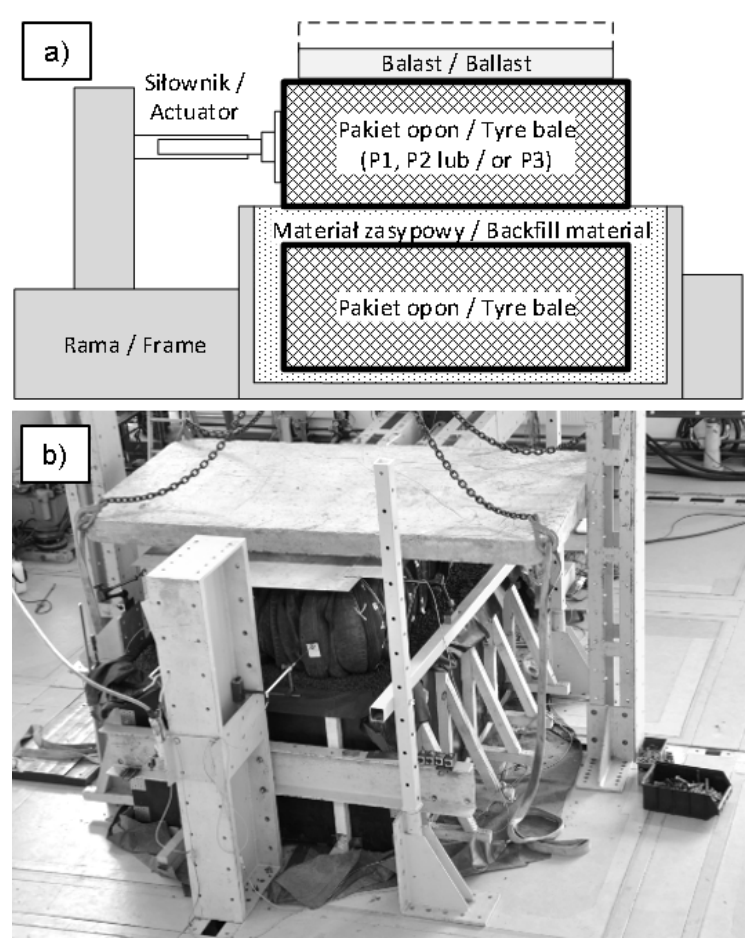

Rys. 2. Schemat stanowiska badawczego (a), stanowisko badawcze w trakcie badań (b)

Fig. 2. Scheme of test stand (a), test stand during testing (b)

\section{Przebieg i zakres badań}

Brak jest standardowych procedur badawczych dla określenia parametrów mechanicznych geokompozytów z wykorzystaniem pakietów SZOS. Jest to materiał w nowej formie technologicznej pakietów o dużych wymiarach, typowych dla elementów konstrukcyjnych, i stosunkowo małej sztywności zbliżonej do parametrów gruntów. Z tych względów w badaniach geokompozytu z pakietami SZOS nie mają wprost zastosowania znane procedury badań elementów konstrukcyjnych lub/i gruntów i kruszyw. Przeprowadzone badanie wymagało opracowania nowej procedury badawczej i indywidualnego planu badań. W badaniach wytrzymałości na ścinanie geokompozytu wykorzystano ogólną ideę badań wytrzymałości na ścinanie gruntów w aparacie bezpośredniego ścinania według PKN-CEN (2009). Procedura wykorzystuje zależność:

$$
\tau=\sigma \cdot \operatorname{tg} \varphi+c
$$

gdzie: $\tau$-naprężenie styczne,

$\sigma$ - naprężenie normalne,

$\varphi$ - kąt tarcia wewnętrznego,

$c$ - spójność (pomijalna w przypadku gruntów niespoistych). 
Duda, A., Sobala, D. i Siwowski,T. (2017). Badania wytrzymałości na ścinanie geokompozytów wykonanych z pakietów sprasowanych zużytych opon i materiału zasypowego. Acta Sci. Pol. Architectura, 16 (3), 3-12. doi: 10.22630/ASPA.2017.16.3.01.

Dla odróżnienia od badań gruntów w badaniach geokompozytu przyjęto, że $\varphi$ oznaczać będzie kąt tarcia, jaki występuje na styku pakietów z materiałem zasypowym lub w samej warstwie materiału zasypowego.

Zaplanowano badanie składające się z trzech etapów (rys. 3):

I - etap przyrostu wartości obciążenia poziomego przykładanego do pakietu SZOS,

II - etap utrzymania obciążenia (przemieszczenia tłoka) po stwierdzeniu wystąpienia poślizgu na lub w materiale zasypowym aż do ustabilizowania się wartości siły ścinającej na siłowniku,

III - etap odciążenia.

Dla każdego rodzaju materiału zasypowego zaplanowano i wykonano łącznie 12 badań w trzech cyklach. Poszczególne badania w cyklu różniły się ciężarem wykorzystanego balastu. Dla każdej próbki badawczej (P1, P2, P3) przewidziano badania przy 4 poziomach obciążenia według tabeli 4.

Tabela 4. Charakterystyka cykli badań

Table 4. Characteristics of test cycles

\begin{tabular}{|c|c|c|c|c|c|}
\hline $\begin{array}{l}\text { Cykl badania } \\
\text { Test cycle }\end{array}$ & $\begin{array}{c}\text { Oznaczenie próbek } \\
\text { Specimen designation } \\
{[-]}\end{array}$ & $\begin{array}{c}\text { Materiał zasypowy } \\
\text { Backfill material }^{\mathrm{a}} \\
{[-]}\end{array}$ & $\begin{array}{c}\text { Balast } \\
\text { Ballast } \\
{[\mathrm{kN}]}\end{array}$ & $\begin{array}{c}\text { Nacisk na strefę } \\
\text { kontaktową }^{\mathrm{b}} \\
\text { Pressure in contact } \\
\text { zone }^{\mathrm{b}} \\
{[\mathrm{kN}]}\end{array}$ & $\begin{array}{c}\text { Prędkość wysuwu } \\
\text { siłownika } \\
\text { Speed extension } \\
\text { of actuator } \\
{\left[\mathrm{mm} \cdot \mathrm{min}^{-1}\right]}\end{array}$ \\
\hline 1 & $\mathrm{P} 1, \mathrm{P} 2, \mathrm{P} 3$ & $\mathrm{~S} 1, \mathrm{~S} 2, \mathrm{~S} 3$ & 10 & 22,2 & 4,0 \\
\hline 2 & $\mathrm{P} 1, \mathrm{P} 2, \mathrm{P} 3$ & $\mathrm{~S} 1, \mathrm{~S} 2, \mathrm{~S} 3$ & 16,2 & 28,4 & 4,0 \\
\hline 3 & $\mathrm{P} 1, \mathrm{P} 2, \mathrm{P} 3$ & $\mathrm{~S} 1, \mathrm{~S} 2, \mathrm{~S} 3$ & 26,2 & 38,4 & 4,0 \\
\hline 4 & $\mathrm{P} 1, \mathrm{P} 2, \mathrm{P} 3$ & $\mathrm{~S} 1, \mathrm{~S} 2, \mathrm{~S} 3$ & 31,8 & 44,0 & 4,0 \\
\hline
\end{tabular}

${ }^{a}$ Materiał zasypowy: S1 - keramzyt, S2 - kruszywo gumowe, S3 - piasek średni.

${ }^{\text {a }}$ Backfill material: S1 - LECA, S2 - TDA, S3 - medium sand.

${ }^{\mathrm{b}}$ Nacisk na strefę kontaktową = ciężar próbki + ciężar płyty dociskowej + balast

${ }^{\mathrm{b}}$ Pressure in contact zone $=$ weight specimen + weight of platen + ballast.

Podczas badań przeprowadzono następujące pomiary:

- przemieszczenia tłoka siłownika poziomego, pomiar ciągły z wykorzystaniem wbudowanego w siłownik czujnika indukcyjnego o zakresie pomiarowym $0 \div 400 \mathrm{~mm}$,

- wartości siły przekazywanej z tłoka na próbkę, pomiar ciągły wbudowanym czujnikiem siły o zakresie pomiarowym $0 \div 40 \mathrm{kN}$,

- przemieszczenia pionowego i poziomego (deformacji) badanego pakietu z wykorzystaniem 8 czujników indukcyjnych, w tym 4 czujników o zakresie pomiarowym $0 \div 100 \mathrm{~mm}$ do pomiaru przemieszczeń pionowych stalowej płyty dociskowej po przyłożeniu balastu oraz 4 czujników o zakresie pomiarowym $0 \div 300 \mathrm{~mm}$ do pomiaru przemieszczeń poziomych na przedniej stalowej płycie dociskowej ( 2 czujniki) i na tylnej powierzchni badanego pakietu ( 2 czujniki).

Rejestracja wszystkich wyników pomiarów odbywała się automatycznie z częstotliwością nie mniejszą niż 0,5 Hz. Dane pomiarowe były zbierane za pomocą systemu akwizycji HBM typu Spider.

W cyklu obciążenia realizowanym w etapie I (rys. 3) następowała deformacja postaciowa i przesunięcie pakietu wraz z balastem po materiale zasypowym (piasek średni, TDA lub keramzyt) do momentu przekroczenia wytrzymałości na ścinanie. Na podstawie przeprowadzonych wcześniej prób wstępnych przyjęto i zrealizowano w badaniach stałą prędkością wysuwu tłoka siłownika, równą $4 \mathrm{~mm} \cdot \mathrm{min}^{-1}$. Wstępne próby przeprowadzone z prędkością $2 \mathrm{~mm} \cdot \mathrm{min}^{-1}$ nie wykazywały różnic w uzyskiwanych wynikach, a znacząco wydłużały cykl badań 
Duda, A., Sobala, D. i Siwowski, T. (2017). Badania wytrzymałości na ścinanie geokompozytów wykonanych z pakietów sprasowanych zużytych opon i materiału zasypowego. Acta Sci. Pol. Architectura, 16 (3), 3-12. doi: 10.22630/ASPA.2017.16.3.01.

i skracały czas dostępny na pracochłonną przebudowę stanowiska. Za moment przekroczenia wytrzymałości na ścinanie (poślizg) próbki przyjęto stan, w którym przemieszczeniu próbki towarzyszy zmniejszenie wartości obciążenia lub przemieszczenie próbki przekroczy $8 \div 10 \%$ jej długości, tj. wartości około $160 \div 200 \mathrm{~mm}$.

Etap II badania (rys. 3) z zatrzymanym przemieszczeniem tłoka siłownika trwał około 5 min lub do momentu ustabilizowania siły ścinającej. Następnie, w etapie III, próbkę odciążano z prędkością $10 \mathrm{~mm} \cdot \mathrm{min}^{-1}$ (rys. 3).

\section{WYNIKI}

Na rysunku 4 przedstawiono wyniki badań próbki P2, przeprowadzonych w trzech cyklach dla różnych warstw kontaktowych i różnych wartości obciążenia balastem. Wykresy przedstawiają zależność siły poziomej $(F)$ od przemieszenia $(\Delta)$ w poszczególnych etapach. Każda linia na wykresie przedstawia wyniki uzyskane $\mathrm{w}$ trakcie realizacji trzech etapów badania. Na wykresach zaznaczono przyjęta $\mathrm{w}$ dalszej analizie trwałą wartość siły ścinającej $\left(F_{t}\right)$, którą wykorzystano dla określenia parametrów mechanicznych geokompozytu. Siłę $F_{\text {t }}$ przyjęto jako równa sile $\mathrm{w}$ siłowniku na początku III etapu badania (rys. 3). Wartość $F_{t}$ wynika z zadanej prędkości przyrostu przemieszczenia tłoka poziomego równego $4 \mathrm{~mm} \cdot \mathrm{min}^{-1}$. W przypadku gdy prędkość przemieszczenia tłoka jest znacznie mniejsza (na poziomie $0,1 \mathrm{~mm} \cdot \mathrm{min}^{-1}$ lub wolniej), moment poślizgu uzyskuje się przy mniejszej sile ścinającej, zatem przyjęta trwała siła ścinająca jest co najwyżej równa charakterystycznej sile wywołującej poślizg. Wniosek ten wynika z obserwacji przebiegu ścieżki obciążenia, utrzymania przemieszczenia i odciążenia próbki, ma uzasadnienie $\mathrm{w}$ rzeczywistej pracy gruntów w masywie ziemnym, a także obserwowany jest $\mathrm{w}$ badaniach innych materiałów konstrukcyjnych (zjawisko relaksacji).

Dla każdego materiału zasypowego S1, S2 i S3 otrzymano co najmniej 4 wartości trwałej siły ścinającej $(F)$. Dla trzech próbek otrzymano łącznie 12 wyników, które naniesiono na wykres zależności siły ścinającej $(F)$ od siły normalnej $(N)$ lub naprężenia ścinającego $(\tau)$
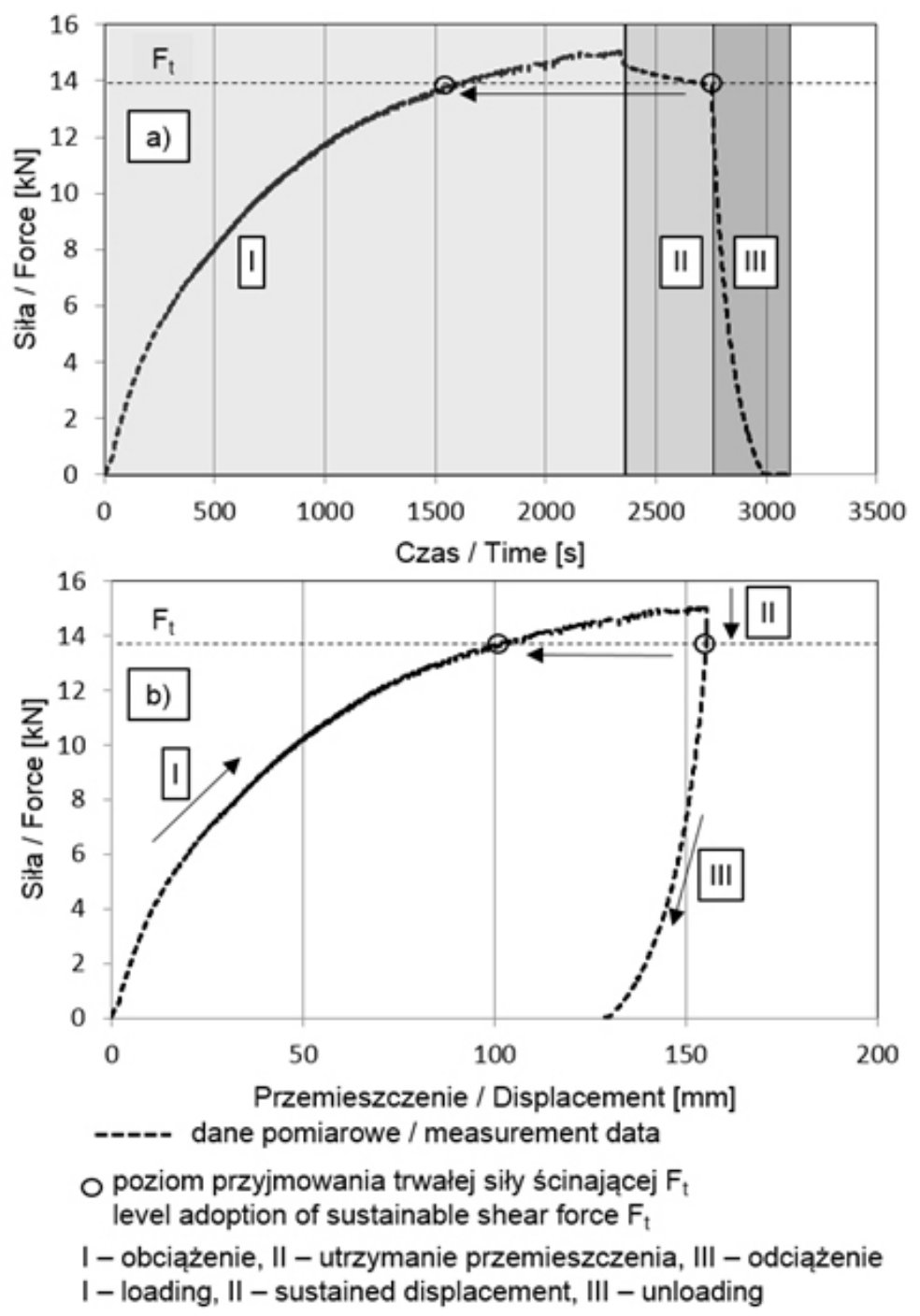

Rys. 3. Badanie wytrzymałości na ścinanie $\mathrm{z}$ podziałem na etapy dla próbki P2/S3 - 22,2 kN: a - zależność siły od czasu, b - zależność siły od przemieszczenia

Fig. 3. Shear strength test with phases for specimen $\mathrm{P} 2 / \mathrm{S} 3-22.2 \mathrm{kN}$ : $\mathrm{a}$ - force - time relation, $\mathrm{b}$ - force - displacement relation 

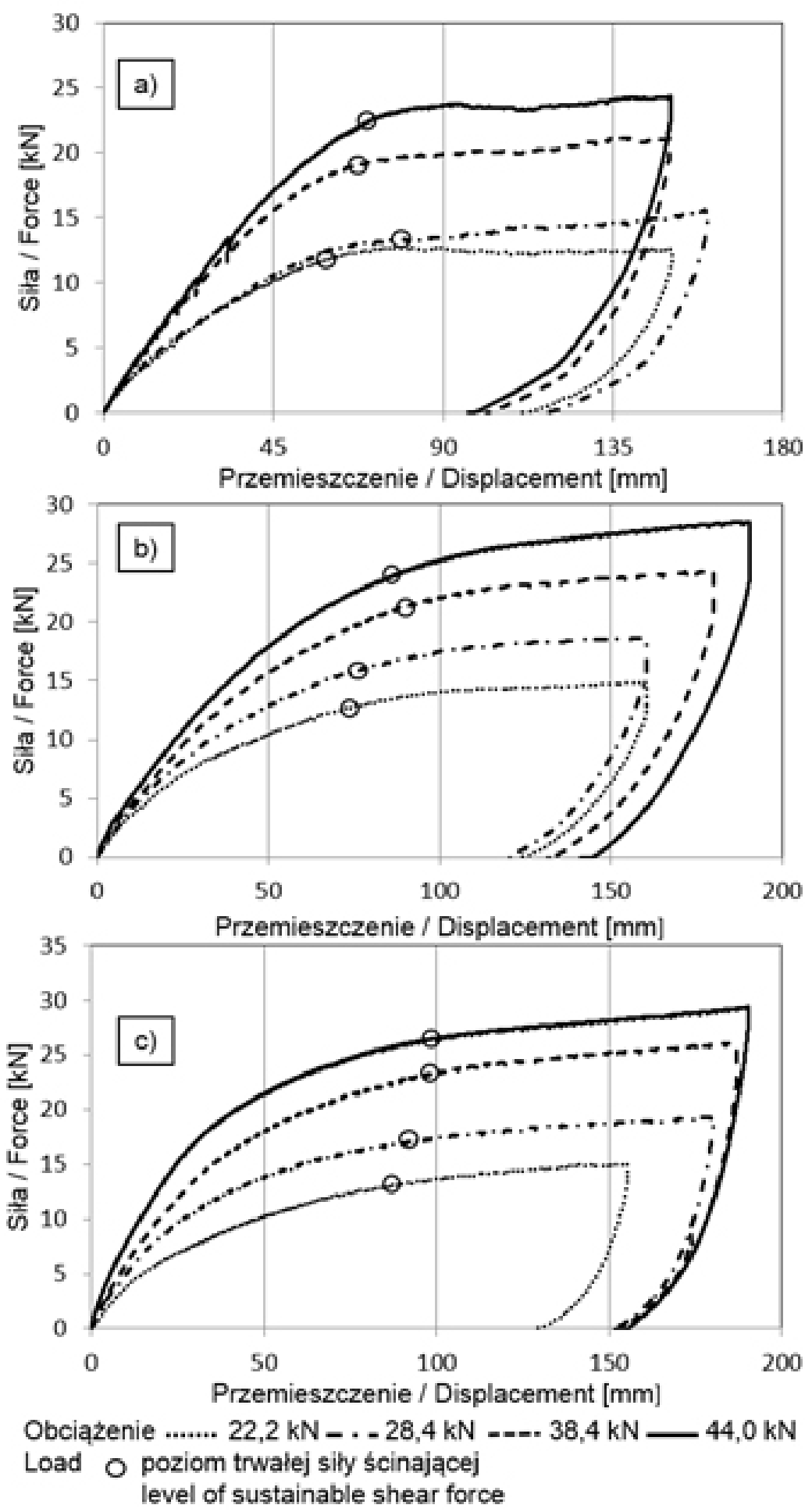

Rys. 4. Zbiorcze wykresy badania wytrzymałości na ścinanie próbki P2 dla materiałów zasypowych: a - keramzytu, $\mathrm{b}$ - kruszywa gumowego, c - piasku średniego

Fig. 4. Summary of shear strength test of specimen P2 for backfill materials: $a-$ LECA, $b-T D A, c-$ medium sand 
Duda, A., Sobala, D. i Siwowski, T. (2017). Badania wytrzymałości na ścinanie geokompozytów wykonanych z pakietów sprasowanych zużytych opon i materiału zasypowego. Acta Sci. Pol. Architectura, 16 (3), 3-12. doi: 10.22630/ASPA.2017.16.3.01.

od naprężenia normalnego $(\sigma)$ w postaci punktów. Wykorzystując sporządzone wykresy i metodę najmniejszych kwadratów, określono przebieg prostej aproksymującej punkty pomiarowe. Ponadto sprawdzono odchylenia punktów od wyznaczonej prostej, które nie przekraczają $25 \%$ wyznaczonej wartości naprężenia stycznego $\tau$ lub nominalnej siły ścinającej. Opisaną procedurę zaadaptowano z normy PKN-CEN (2009). Na rysunku 5 przedstawiono wyniki przeprowadzonej analizy i podano równania prostych aproksymujących oraz wartość kątów tarcia określonych na podstawie ich nachylenia.
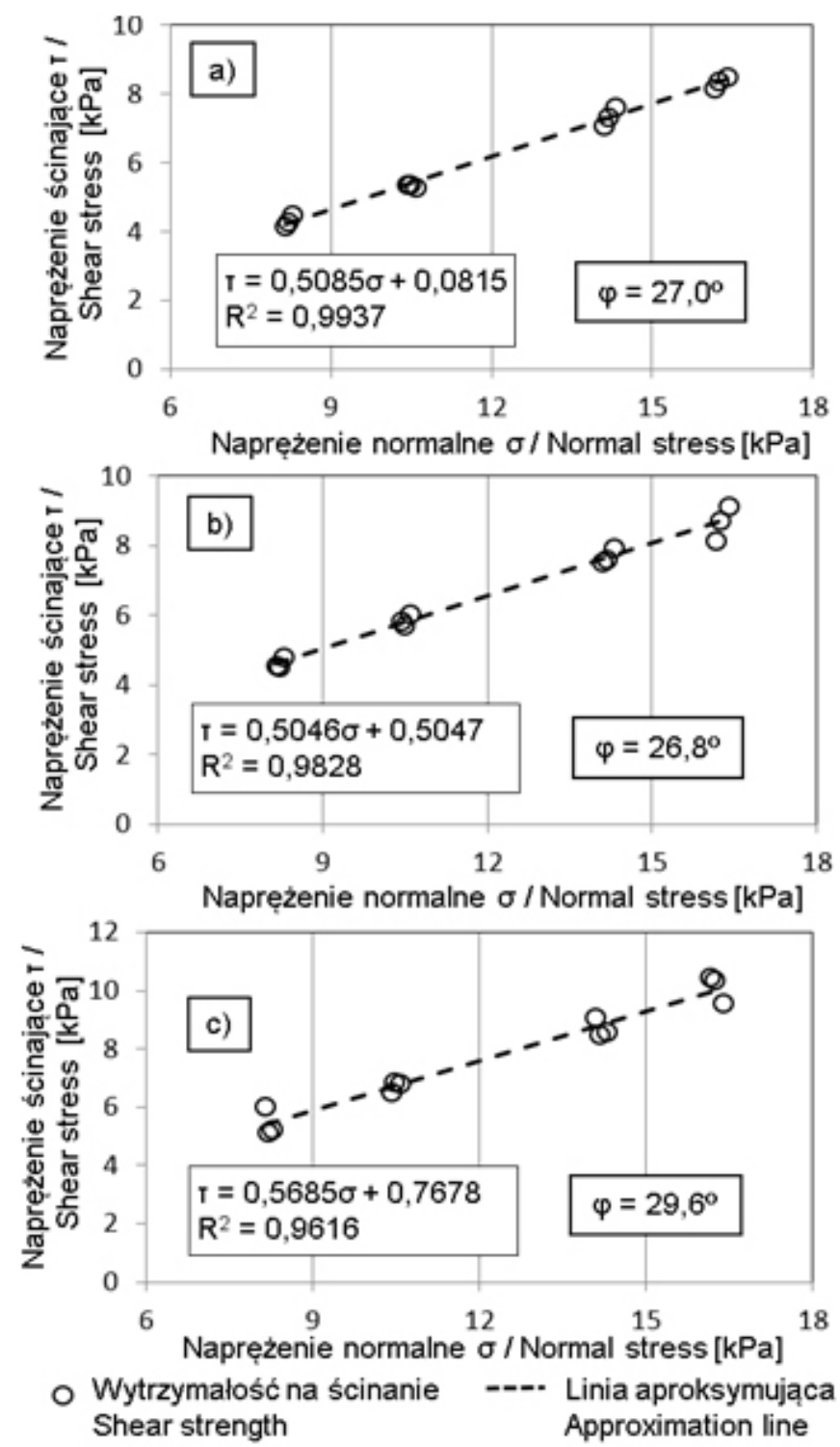

$\mathrm{R}^{2}$ - wspólczynnik determinacji / determination coefficient $\varphi$ - kąt tarcia warstwy kontaktowej/ friction angle of interface layer

Rys. 5. Parametry mechaniczne strefy kontaktowej dla materiałów zasypowych: a - keramzytu, b - kruszywa gumowego, $\mathrm{c}$ - piasku średniego

Fig. 5. Mechanical parameters of the interface layer for backfill materials: $a-$ LECA, $b-$ TDA, $c-$ medium sand 
Duda, A., Sobala, D. i Siwowski,T. (2017). Badania wytrzymałości na ścinanie geokompozytów wykonanych z pakietów sprasowanych zużytych opon i materiału zasypowego. Acta Sci. Pol. Architectura, 16 (3), 3-12. doi: 10.22630/ASPA.2017.16.3.01.

Określonym w badaniach wartościom trwałej wytrzymałości na ścinanie $\left(F_{t}\right)$ towarzyszą przemieszczenia

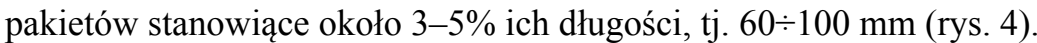

\section{WNIOSKI}

Badania pozwoliły ustalić zastępcze wartości kąta tarcia $(\varphi)$ oraz spójności $(c)$ dla geokompozytów złożonych z pakietów SZOS i materiałów zasypowych z keramzytu geotechnicznego, z mieszanki chipsów i granulatu gumowego (TDA) oraz z piasku średniego (tab. 5).

Tabela 5. Parametry mechaniczne Coulomba-Mohra dla geokompozytu złożonego z pakietów SZOS i materiałów zasypowych

Table 5. Mohr-Coulomb strength parameters for geocomposite consisting of tire bales and backfill materials

\begin{tabular}{|c|c|c|c|c|}
\hline $\begin{array}{l}\text { Materiał zasypowy } \\
\text { Backfill material }\end{array}$ & $\begin{array}{l}\text { Warunki wilgotnoś- } \\
\text { ciowe } \\
\text { Moisture conditions } \\
{[-]}\end{array}$ & $\begin{array}{c}\text { Kąt tarcia, } \varphi \\
\text { Friction angle, } \varphi \\
{\left[{ }^{\circ}\right]}\end{array}$ & $\begin{array}{c}\text { Spójność, } c \\
\text { Cohesion, } c \\
{[\mathrm{kPa}]}\end{array}$ & $\begin{array}{c}\text { Wartość współczynnika } \\
\text { determinacji, } \mathrm{R}^{2} \\
\text { Determination } \\
\text { coefficient, } \mathrm{R}^{2} \\
{[-]}\end{array}$ \\
\hline $\begin{array}{l}\text { Keramzyt } \\
\text { LECA }\end{array}$ & $\begin{array}{l}\text { wilgotne } \\
\text { wet }\end{array}$ & 27,0 & 0,08 & 0,994 \\
\hline $\begin{array}{l}\text { Kruszywo gumowe } \\
\text { TDA }\end{array}$ & $\begin{array}{l}\text { wilgotne } \\
\text { wet }\end{array}$ & 26,8 & 0,50 & 0,983 \\
\hline $\begin{array}{l}\text { Piasek średni } \\
\text { Medium sand }\end{array}$ & $\begin{array}{l}\text { wilgotne } \\
\text { wet }\end{array}$ & 29,6 & 0,77 & 0,962 \\
\hline
\end{tabular}

Wartości parametrów zastępczych dla geokompozytów określone w badaniach charakteryzuje bardzo dobre dopasowanie do prostych aproksymujących, opisane dużymi wartościami współczynnika determinacji $\left(\mathrm{R}^{2}>0,96\right)$. Określone w badaniach zastępcze wartości kąta tarcia $(\varphi)$ oraz spójności $(c)$ dla pakietów SZOS są większe niż uzyskiwane przy współpracy badanych materiałów zasypowych z betonem, stalą i drewnem. Największe wartości badanych parametrów geokompozytu uzyskano dla piasku średniego, będącego jednocześnie najtańszym i najczęściej wykorzystywanym materiałem w komunikacyjnych budowlach ziemnych.

Wyniki przeprowadzonych badań wskazują na możliwość efektywnego wykorzystania pakietów SZOS w budownictwie komunikacyjnym.

\section{ADNOTACJA}

Badania wykonano w ramach projektu współfinansowanego ze środków Europejskiego Funduszu Rozwoju Regionalnego „ReUse - Innowacyjne materiały z recyklingu, zwiększające trwałość obiektów mostowych” (Innotech $\mathrm{nr}$ K3/IN3/38/228116/NCBiR/15), realizowanego przez konsorcjum złożone $\mathrm{z}$ firm Remost Dębica sp. z o.o., Promost Consulting sp. z o.o. sp. k. (lider konsorcjum), Geotech Rzeszów sp. z o.o. oraz Politechnikę Rzeszowską.

\section{PIŚMIENNICTWO}

Duda, A. i Trojnar, K. (2016). Wykorzystanie zużytych opon samochodowych w budownictwie komunikacyjnym. Materiały Budowlane, 7, 80-82. doi: 10.15199/33.2016.07.26. 
Duda, A., Sobala, D. i Siwowski, T. (2017). Badania wytrzymałości na ścinanie geokompozytów wykonanych z pakietów sprasowanych zużytych opon i materiału zasypowego. Acta Sci. Pol. Architectura, 16 (3), 3-12. doi: 10.22630/ASPA.2017.16.3.01.

Duda, A., Sobala, D., Siwowski, T. i Kaleta, D. (2016). Wykorzystanie materiałów z recyklingu opon samochodowych w budownictwie komunikacyjnym. Archiwum Instytutu Inżynierii Ladowej, 21, 97-111.

Geosyntec Consultants, Inc. (2008). Guidance Manual for Engineering Uses of Scrap Tires, Maryland Environmental Service, Annapolis, Maryland.

PAS 108:2007. Specification for the production of tire bales for use in construction. British Standards Institution.

PKN-CEN ISO/TS 17892-7:2009. Grunty budowlane - badanie na ściskanie gruntów drobnoziarnistych w jednoosiowym stanie naprężenia.

Raport ReUse - Badania wytrzymałości na ścinanie materiałów zasypowych w laboratorium geotechnicznym Geotech Rzeszów sp. z o.o. (materiał niepublikowany).

Zornberg, J. G., Christopher, B. R. i Oosterbaan, M. D. (2005). Tire Bales in Highway Applications: Feasibility and Properties Evaluation. Colorado Department of Transportation, Report No. CDOT-DTD-R-2005-2, Denver, Colorado.

\section{SHEAR STRENGTH TESTS OF GEOCOMPOSITES MADE OF TIRE BALES AND BACKFILL MATERIALS}

\section{ABSTRACT}

Compressed tire bales are a new building material used in the civil engineering and made of recycled car tires. This material is characterized by low unit weight, very good drainage properties and high vibration damping. The aim of the ongoing research is to evaluate interface action of geocomposites made of tire bales and filling materials (TDA, LECA, sand) used in earth structures for transport infrastructure. Research on the friction/slip between the rubber and the filling materials as well as the shear strength tests of tire bales have been conducted. The results have shown a high shear resistance between tire bales and filling materials and confirmed the possibility of technically efficient use of the new material in the earth structures.

Key words: tire recycling, tire (tyre) bales, geocomposite, backfill materials, earth structures 